\title{
The role of imaging, deliberate practice, structure, and improvisation in approaching surgical perfection
}

\author{
Joseph A. Dearani, MD, ${ }^{a}$ Michael Gold, PhD, ${ }^{b}$ Bradley C. Leibovich, MD, ${ }^{\mathrm{c}} \mathrm{K}$. Anders Ericsson, PhD, ${ }^{\mathrm{d}}$ \\ Kamal R. Khabbaz, MD, ${ }^{\mathrm{e}}$ Thomas A. Foley, MD, ${ }^{\mathrm{f}}$ Paul R. Julsrud, MD, Jane M. Matsumoto, MD, ${ }^{\mathrm{f}}$ and \\ Richard C. Daly, MD
}

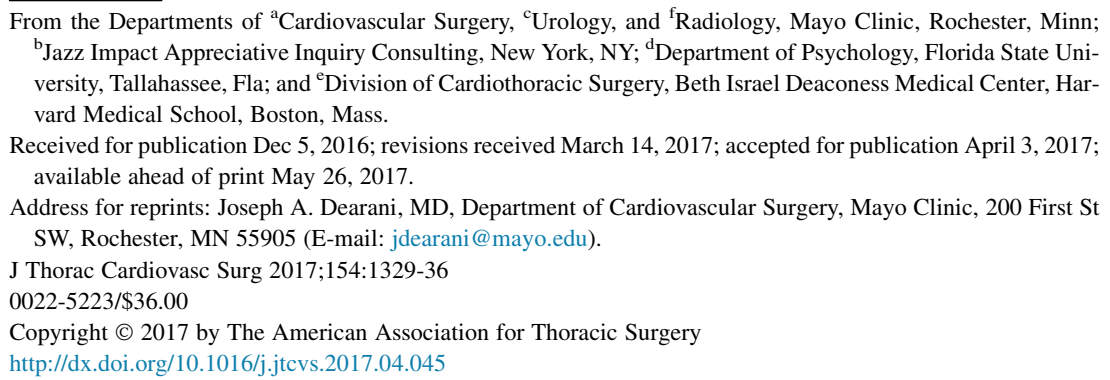

The first 50 years of cardiovascular surgery (CVS) were characterized by the development of new operations with progressive improvement in outcomes. Improvement in imaging techniques, particularly 3-dimensional (3D) imaging, facilitates surgical planning. The steps of an operation can range from highly predictable to markedly variable depending on the complexity of the defect. The orchestration of an operation includes structured steps and improvised steps. Superior performance and genuine expertise requires deliberate practice (DP), which involves improving the skills you already have and extending the reach and range of your skills. DP is defined as focused and repeated tasks to improve performance with coaching and immediate feedback. ${ }^{1,2}$ Current expectations by the public and the profession for perfection in health care emphasize the importance of continuous improvement with ongoing training and mentoring of surgical teams to improve outcome. The purpose of this review is to highlight the critical connection among advanced imaging, DP, structure, and improvisation as an approach to achieving surgical perfection.

\section{CARDIAC SURGERY: THEN AND NOW}

The earliest era of CVS (1950s-1970s) was marked by the application of cardiopulmonary bypass for intracardiac repair of congenital heart defects (eg, tetralogy of Fallot). Imaging included $\mathrm{x}$-ray fluoroscopy and cardiac catheterization. Anatomic detail was unsophisticated. Relatively few institutions performed CVS, and operative mortality was high (25\%-50\%). In the mid-1970s, outcomes improved with the development of cardioplegia for myocardial protection. Despite improving results, the decision to not offer surgery for some complex lesions was not uncommon. Ultrasound (echocardiography), computed tomography (CT), and magnetic resonance imaging (MRI) started to be used clinically in the 1970s, but mainly for noncardiac

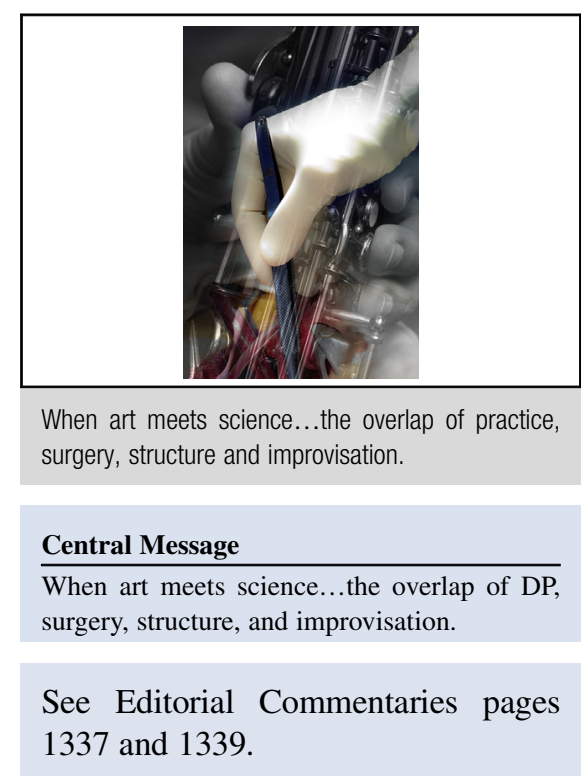

applications. Cardiac applications using these technologies began in earnest in the 1980s.

The 1980s were notable for neonatal corrective procedures (eg, arterial switch). Imaging improved with the use of transesophageal echocardiography (TEE), and operative mortality was less than $10 \%$ for many lesions. As the pace of innovation plateaued, emphasis shifted to improving early outcome. Procedures were now available in most metropolitan areas as children's hospitals proliferated and hope and gratitude emerged for patients with more complex defects.

Today, CVS uses sophisticated imaging (echocardiography, CT, and MRI) with virtual or printed models available on request for surgical planning or education. Surgery is almost always offered even for the most complex defects. There is now pressure for perfection to further reduce operative mortality to less than $2 \%$, and public reporting of outcomes are becoming universal.

Despite expectations for near perfection in surgical outcome, graduate medical education is being transformed from a time-based apprenticeship into a competency-based model. This paradigm change, coupled with restrictions on resident duty hours, has generated a need to focus training. ${ }^{3,4}$ Patients come to hospitals for treatment and not to aid education, and patient safety and quality of care priorities far outweigh clinical training requirements. In this context, it is challenging to acquire proficiency in 
surgical procedures that require repetitive exposure and complex integration of cognitive knowledge with manual dexterity. Although simulators have been used, their role is limited to acquisition of basic surgical skills. However, there is evidence of clinical transferability of these simulator-acquired skills, and their efficacy and value have been established. ${ }^{5-7}$

\section{ADVANCED IMAGING}

The development of ultrasound, CT, and MRI allowed for the advancement from planar (2-dimensional) imaging to volumetric (3D) imaging. Current technology allows for high-resolution, 3D analysis of cardiac structure and physiology. CT and MRI both have undergone significant advancement since the introduction in the 1970s. Both initially produced low-resolution images that took minutes to obtain and hours to process. Present-generation CT scanners can image the heart in seconds with submillimeter resolution. ${ }^{8}$ Current MRI allows for high-resolution images with high spatial and temporal resolution to be obtained and can be used to measure intracardiac flows. ${ }^{8,9}$ Three-dimensional volumetric image datasets can be obtained with both modalities that allow cardiac and surrounding structures to be viewed in any plane or in 3D representations.

The 3D volumetric imaging data, combined with other new technologies, is being used to advance preoperative planning. Using a 3D printer to create detailed physical models provides a more intuitive replica of complex anatomy (Figure 1). In addition, anatomic and flow data provided from this advanced imaging can be combined with advanced computer simulation techniques and allow surgical procedures to be virtually simulated. Such simulations could facilitate the optimal preoperative planning of surgical procedures, for example, optimal Fontan conduit geometry, to be determined virtually by simulating flow through multiple conduit geometries before actual surgery. ${ }^{10}$

\section{Doing the Operation Before Doing the Operation}

In addition to 3D imaging to better understand the anatomy to facilitate an operation, 3D models can be printed in advance to allow practice of the procedure before entering the operating room. Expertise in CVS, for example, mitral valve (MV) repair, requires years of training and practice. Despite being performed worldwide, surgical management of MV disease is not uniform across centers and surgeons. ${ }^{11}$ Because each MV is anatomically and functionally unique and can be operated on only once in a given patient, there are limited opportunities to practice MV repair techniques. The options for simulator-based DP of MV repair techniques are limited. Virtual and in vitro animal models have been used for MV repair training. ${ }^{12,13}$ These generic task trainers have limited external validity in the clinical setting because they lack patient specific anatomic peculiarities that require a modification of surgical technique. Therefore, the current model of training in MV surgery is based on a prolonged period of observation with limited participation in the actual surgical procedure. This variation in trainee exposure may explain the unpredictable nature of MV repair and surgical results.

Patient-specific abnormalities, for example, MV pathology or hypertrophic cardiomyopathy, are printed using 3D TEE or CT data. ${ }^{14-17}$ This is followed by 3D printing of

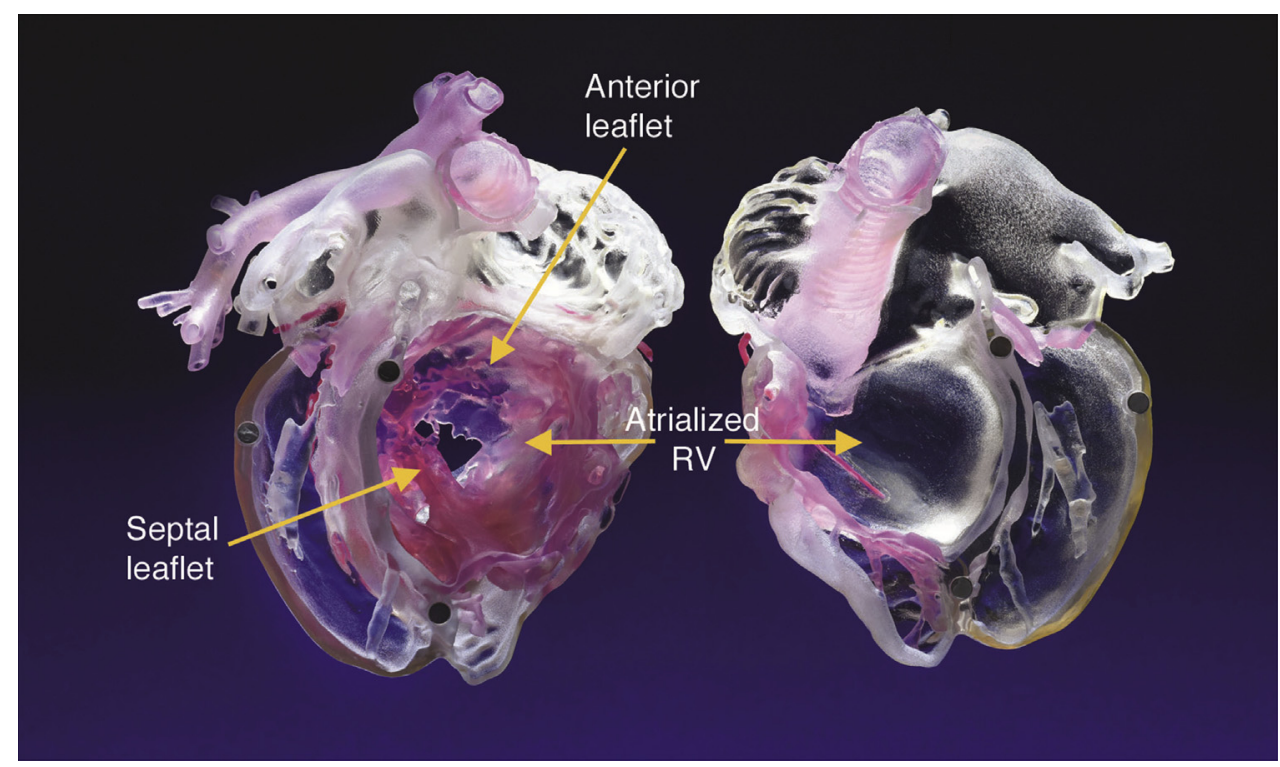

FIGURE 1. 3D virtual printed model of a heart with Ebstein anomaly. $R V$, Right ventricle. 

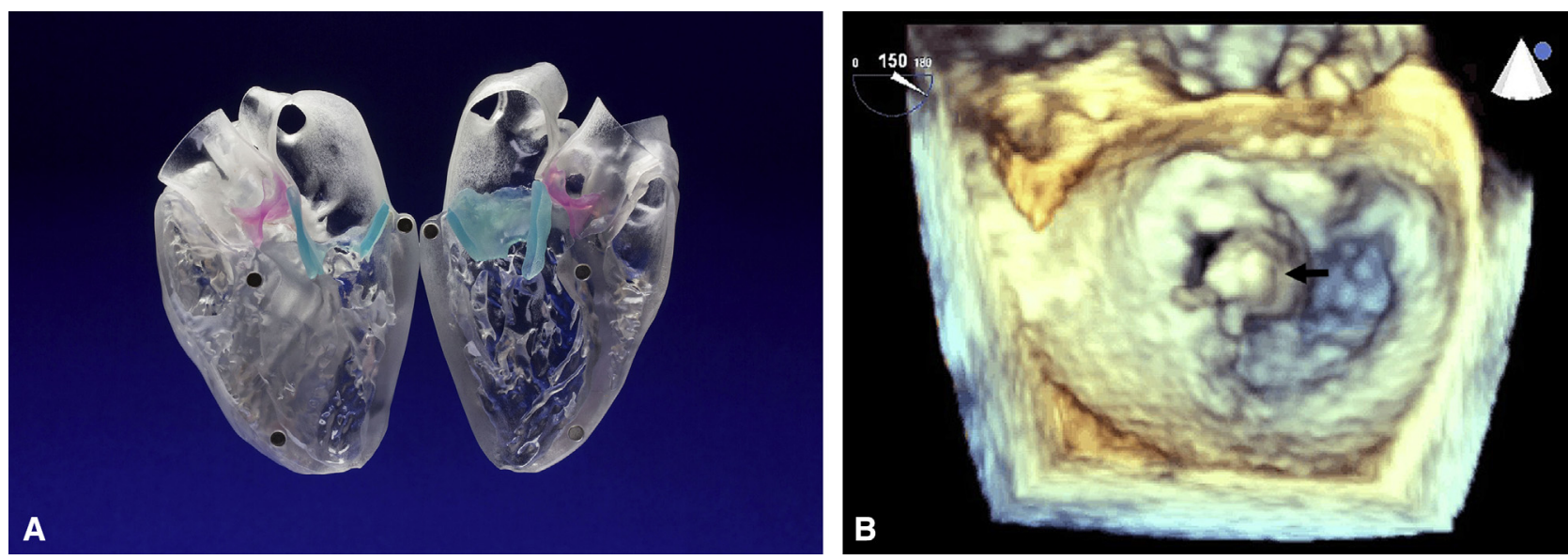

FIGURE 2. A, 3D printed model of a normal MV (shown in blue) obtained from CT imaging data. B, 3D TEE of the MV from the left atrial perspective. The black arrow is pointing at a flail middle scallop of the anterior mitral leaflet (A2) with several torn chordae tendineae also seen attached to the flail scallop.

the heart with MV leaflets/subvalvar apparatus demonstrating the abnormality (Figure 2, A). In the setting of obstructive hypertrophic cardiomyopathy, dimensions of the ventricular septum (thickness, extent down into the ventricle, free wall thickness) in addition to MV abnormalities are identified in the 3D printed model. With advancing technology, individual anatomic areas of the heart or complete heart models with realistic tissue thickness and consistency are created and available for education or preoperative rehearsal.

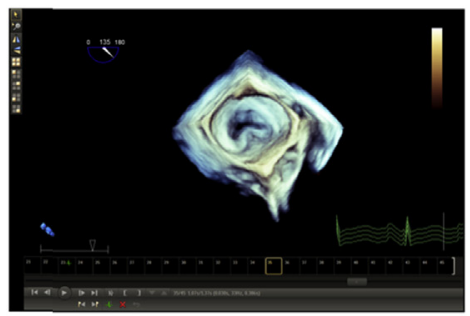

A
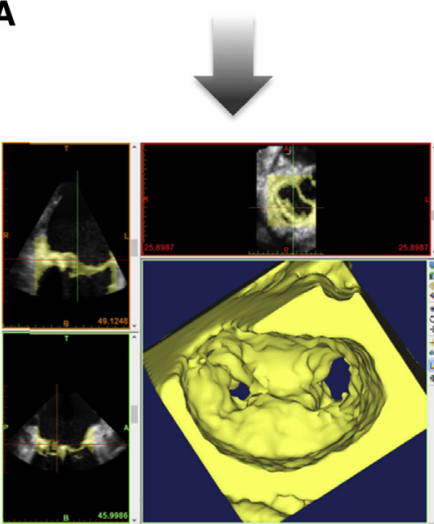

B

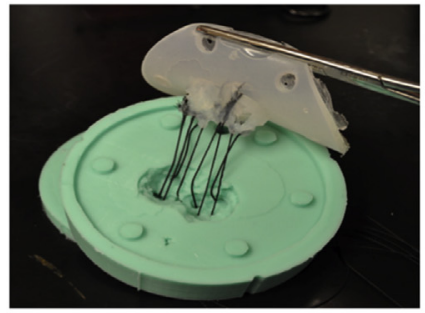

D

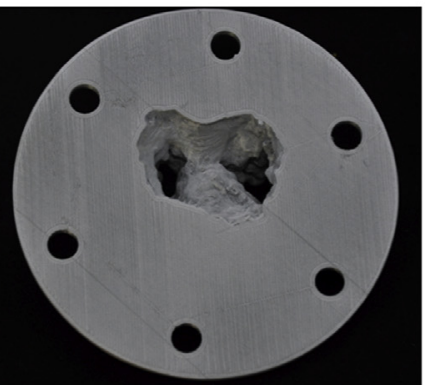

C

In the setting of the MV, the TEE-generated model (Figure 2, B) can be hemodynamically tested and imaged in a pulse duplicator (Figure 3 ). ${ }^{18}$ With the image acquisition to print time becoming shorter, 3D printing of the pathologic abnormality (eg, the MV) is becoming point of care in nature. Tangible models of patient specific MV pathology can be printed before the operation. Trainees can execute the planned technique with immediate feedback and opportunities for repeated refinement before the actual operation and then duplicate the observed technique after the

FIGURE 3. Using 3D printed MV in a hemodynamic testing chamber. A, Data from the 3D TEE machine are obtained and converted to Cartesian DICOMs using Philips Qlab (Philips Medical Systems, Andover, Mass). B, The data are then imported into Mimics (Materialise, Leuven, Belgium) for segmentation of the MV. Once segmented, the data are exported as a stereo lithography file to 3matic (Materialise, Leuven, Belgium) and loaded onto a flange (C) that is used to generate a flexible silicone model of the MV (D), which could then be used for hemodynamic testing in the pulse duplicator (E). 
procedure. Therefore, it is possible to create a patient specific MV model for DP before and after the operation.

It is also possible to use videos of prior operations, where trainees practice on a given MV model until mastery, watch the video, and then duplicate the observed procedure on the model. When a trainee identifies a particular technical problem, it is possible to provide a list of relevant cases from a library of past cases that facilitates remediation. The use of past cases with video/audiotapes and immediate instructor feedback has been applied in medicine. ${ }^{19}$ Gradual accumulation of data could introduce an element of uniformity of MV repair techniques. This leads to consistency of techniques among surgeons and may allow validation and comparison of new repair techniques and could ultimately play a role in eventual best practices. These 3D printed models have the ability to offer simultaneous qualitative and quantitative improvements in surgical training. ${ }^{20-22}$

\section{DELIBERATE PRACTICE AND ACHIEVING EXPERTISE}

Traditional methods of education involving lectures, group discussions, and observing experts' demonstrations are not effective methods for developing superior performance and genuine expertise. Studies have demonstrated how expert musicians developed mastery of their instrument by predominantly engaging in individualized practice activities with immediate feedback that had been designed by their teachers. ${ }^{1,2}$ Improvements in the performer's ability to plan, modify, assess, and evaluate their performance mediate increases in skill. ${ }^{2,19}$ When individuals with superior performance and patient outcomes are identified, their superior performance can be reproduced, replicated, and measured in the laboratory, or in our situation, the hospital environment (outcomes reports, bypass and crossclamp times, morbidity, and mortality).

To attain expert performance, it is necessary for the trainee to engage in substantial, specific, and sustained exercises to do something one does not do well, or perhaps, does not do at all. ${ }^{23}$ If one considers coronary artery bypass grafting as an example in CVS residency, it is reasonable to assume that the senior resident knows how to handle surgical instruments and tie knots. Command of basic skills is essential at this stage, for example, perfecting needle passage through butter that results in a series of dots at the entrance/exit sites as opposed to creating lines/grooves that reflect a lack of honoring the curve of the needle. The more advanced exercise to be practiced now is loading the needle correctly (once), taking the stitch in the precise location (once), following through, and reloading (again, only once) until the anastomosis is completed, that is, optimizing efficiency. Placement of the needle/suture should be precise and consistent from bite to bite. It also requires knowing which bites are more easily done forehand versus backhand. Specifically, DP involves building a complex skill, and after mastery of fundamental skills, the focus turns to progressively more difficult steps. Once this exercise is mastered, the degree of difficulty is increased again. This may include repeating the same exercise with a smaller distal vessel, using a more fragile conduit, or making the exposure more difficult, for example, a deep chest in a large patient.

Expert performance requires acquisition of integrated skills that allow planning, monitoring, and evaluation to gradually refine prior skills. Consequently, there is no qualitative difference between improving preexisting skills and learning a new relevant skill. ${ }^{2,19}$ These 2 tasks require arduous concentration, which limits the amount of time one can spend doing them. The famous violinist Nathan Milstein said, "practice as much as you feel you can accomplish with concentration." Once when I became concerned because others around me practiced all day long, I asked my mentor, Professor Auer how many hours I should practice, and he said, "it really doesn't matter how long. If you practice with your fingers, no amount is enough. If you practice with your head, two hours is plenty."

Simulation as a method to improve surgical skills is now a part of postgraduate medical education. Simulation opportunities in CVS include assessment tools for cognitive knowledge, patient scenarios, disease management, operative planning, technical skills, judgment, leadership, and crisis management. ${ }^{24,25}$ Simulators may be organic or inorganic. ${ }^{26}$ Organic simulators include live animal models or fresh human cadavers; inorganic simulators include synthetic bench models or virtual reality simulators (eg, robotic or bronchoscopy simulators). Simulation, particularly virtual reality simulation, provides a mechanism for immediate performance feedback and objective assessment. Current literature demonstrates that simulation positively correlates with improvements in efficiency and surgical outcomes. $^{5,12,27-33}$

Within the theoretic framework of expert performance, the focus is always on objective measures of performance or patient outcomes. Consequently, the best measure of surgeon performance is analysis of the preplanning procedure, operative video, postoperative result, and long-term patient outcome. A Canadian neurosurgeon analyzed all adverse events for his operations and was able to work with his surgical team to dramatically reduce most adverse events. ${ }^{34}$ Studies of larger groups of cancer surgeons show a learning curve (at least spanning the first 250 operations) for recurrence of prostate cancer after robotic prostatectomy. ${ }^{35,36}$

How much time would be required to reach one's peak performance? ${ }^{37}$ When we look at other domains of expertise besides surgery, there is an interesting relation between amount of practice and performance. Over the last centuries, the amount and quality of practice for musicians and athletes have increased substantially, and in parallel there are large increases in performance. Today, music students are able to perform music pieces that only a single 
musician in the world was able to perform a century ago. Amateur marathon runners are able to match the performance of Olympic medal winners during the first few Olympics.

In most other professions, the most gifted performers need a minimum of 10 years or 10,000 hours before they win international competitions (Figure 4). ${ }^{1}$ This timeline also seems to be similar in surgery. Surgical residency is usually 5 years, and some surgical subspecialties (eg, CVS or neurosurgery) are 6 to 8 years depending on additional subspecialty training. When a surgeon begins practice, it is common knowledge that competence and credibility require a learning curve and timeline of approximately 5 years. Thus, it is reasonable to assume that the time to achieve expertise in a field like CVS is 10 to 15 years (residency and early staff years). In addition to DP by the surgeon, the success of an operation also depends on collaboration and performance of the surgical team. The importance of continued practice and repetition of operations by the (same) team members is essential and results in consummate team experience. This cannot be overemphasized. There are now team training activities in which the trainer induces critical events, for example, interruptions while matching blood types, ${ }^{38}$ and thus life-threatening errors can enhance the ability to react appropriately in the future when untoward events recur.

The most effective way to apply essential aspects of DP to surgical performance involves reviewing videos of actual operations (with/without faculty present) and then analyzing the procedure to identify areas of individual or team performance that could be improved. Once the weaknesses have been identified, DP activities can be designed for improvement outside of the operating room with monitoring during the next operation. The honing of these highly specific skills is an example of how DP could be applied with simulation. Given the complexity of CVS, necessity for teamwork, and the critical nature of outcomes, understanding the difference between the amounts of time spent

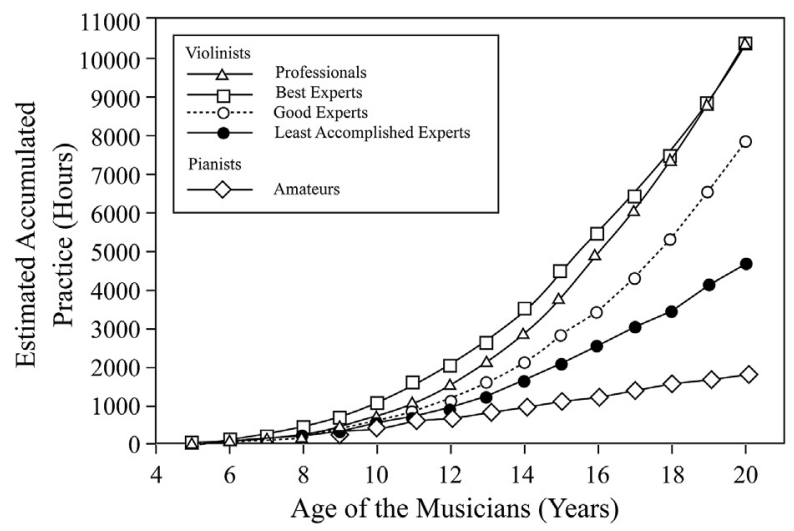

FIGURE 4. The effect of DP for a professional violinist. ${ }^{1}$ versus the acquisition and integration of new knowledge is critical in designing time-sensitive, effective forms of DP.

Instead of the effortful monitoring of actual performance to demonstrate superior outcomes, it has been popular to look for simple solutions to define expertise. In surgery, the surgeon is required to complete a particular number of procedures to be credentialed to practice independently. In support of the "10,000 hour" rule, Gladwell ${ }^{39}$ cited research on musician expertise. ${ }^{21}$ Although this research focused on DP as "the individualized training activities specifically designed by a coach/teacher to improve certain aspects of an individual's performance through repetition and successive refinement." 40

It has been common for scientists to be confused about the definition of DP. In a recent meta-analysis of the relation between amount of accumulated practice and attained achievement, Macnamara and colleagues ${ }^{41}$ estimated the number of hours of DP by including hours attending lectures, hours of group discussion, and hours spent playing matches. In another meta-analysis, Macnamara and colleagues ${ }^{42}$ estimated the accumulated hours in DP in sports by summed hours for playing matches, team practice, watching sports on television, and other activities. ${ }^{43}$ Consequently, these meta-analyses summed hours of all types of practice to form a single sum and found that these sums predicted only approximately $20 \%$ of variance of performance. This estimate does not measure the effectiveness of individualized practice activities with immediate feedback that has been designed by a teacher, and the few estimates for DP are higher. ${ }^{37}$

Even after practice supervised by a teacher stops at the start of independent practice, continuous self-assessment and feedback from peers and mentors are essential to obtain and maintain expertise, particularly surgery. Technical expertise progressively improves with DP and can be quantified by outcome metrics, for example, length of time for dissection, time to perform an anastomosis, bypass and crossclamp times, morbidity, and mortality. However, ultimate success in surgery also requires skills that are more difficult to quantify. These skills include critical thinking, decision-making, and judgment. The combination of technical abilities, team performance, and these other skill sets result in experience. Progressive experience over a career can diminish cognitive effort to perform certain tasks, which allows for the development of increased situational awareness and intraoperative flexibility as the surgeon/team spend less cognitive effort on those portions that have been practiced and mastered.

\section{STRUCTURE AND IMPROVISATION: THE MUSIC METAPHOR}

Integrating the concepts of structure and improvisation is critical in many professions, for example, sports, games, music, surgery, and life (Figure 5). Structure and 


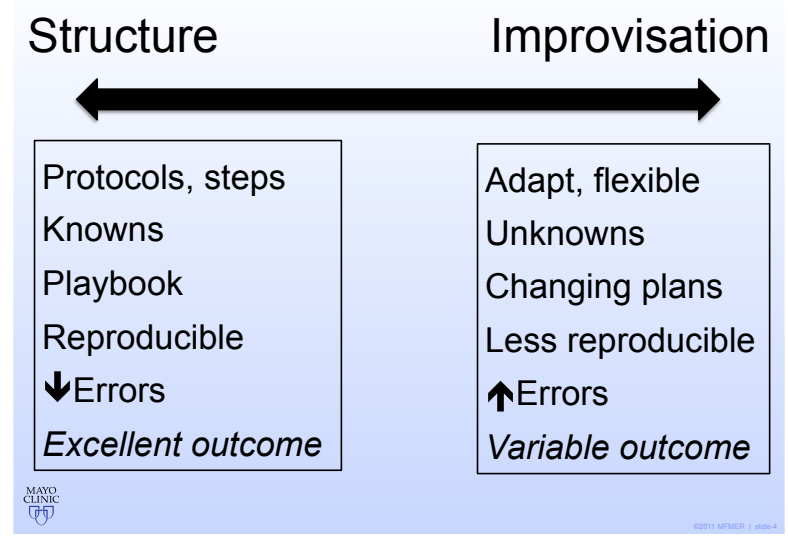

FIGURE 5. Contrast of the structure/improvisation continuum.

improvisation, as they apply to the art of surgery, have a variety of important parallels with the art of jazz improvisation. To introduce this generative metaphor, it may be helpful to distinguish the difference between jazz improvisers and classical musicians (Figure 6).

Structure is intrinsic in nearly every aspect of classical music. The composer creates a score in which every choice of pitch or rhythm is absolutely defined. The performer's job is not to change or improve the information on the score, but to translate from design into music the beauty of an idea that is absolute or closed out in terms of possible outcomes. Beethoven's Fifth Symphony may be performed with greater or lesser esthetic acumen but, note for note, it is always the same musical idea. Classical music has a very high level of predictability and a very low level of improvisation.

In contrast, jazz musicians work in a context of low predictability where both structure and the skill of improvisation are intrinsic. In jazz, there are cognitively held rules

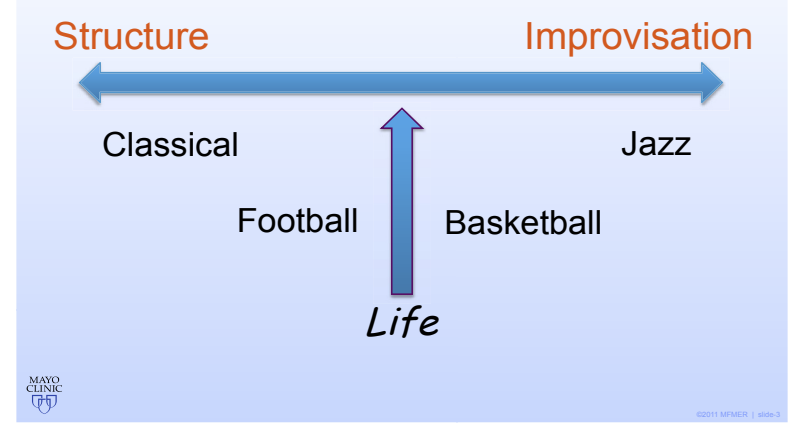

FIGURE 6. The structure/improvisation continuum in music, sports, and life. Some professions are intrinsically more structured, whereas others require more improvisation. for musical innovation. The harmonies and melody of the tune are, in fact, non-negotiable. However, the jazz musician is given the autonomy to interpret the original score and embellish it, and at the time of the solo is permitted to deviate further away from the original score and spontaneously create new music while following the original pattern of harmonic changes. This requires intense acuity in communication, both listening and speaking (with their respective instrument) between the soloist and the other musicians in the ensemble. Great jazz performances occur when whole-system thinking is embraced by everyone involved...cross-functional relationships, real-time sharing of firsthand knowledge, highly attuned skills of listening, and in-the-moment design thinking.

The jazz ensemble is a cohesive team similar, in essence, to the surgical team performing an operation, with the surgeon as the lead instrument or soloist and the other operating room staff functioning as the supporting ensemble. Success of the operation requires communication, familiarity, and intense cross-functional understanding (and experience) by everyone participating. Like jazz, to respond both physically and cognitively to suddenly changing conditions, both mind and body must function as a seamlessly integrated whole.

The highest level of performance in jazz happens when physical technique becomes invisible. During a performance, the musicians are somatically conjoined. Any individual hesitation (mental or physical) has immediate impact on the fluidity of the system as a whole. Improvisation icons such as Louis Armstrong and Charlie Parker demonstrate a quality of deliberation that informs every aspect of their playing. It is understood in jazz, you play what you practice. This concept also applies to the operating theatre, where surgery and the team are analogous to the musical performance and the ensemble. Obviously, we are not suggesting that surgeons and their teams are improvising in the same manner that jazz musicians do, but there are parallels between the 2 disciplines, particularly with regard to DP that can be of practical value. The importance of having a command of structure (music score vs choreography of the operation), basic techniques and repetitions combined with knowledge of potential variables, and unique anatomy/pathology based on modern imaging help anticipate and prepare for improvisation during the procedure.

The relationship between DP and the acquisition of improvisational skills indicates that it is possible to achieve responsive capability that is highly attuned to subtle perceptual information and has a vast array of finely timed and tunable motor programs available. ${ }^{44}$ This results in the qualities of efficiency, fluency, flexibility, and expressiveness. All motor organization functions can be handled without explicit attention to details, and the performer attends almost exclusively to a higher level of emergent expressive control parameters. ${ }^{44-47}$ The preparation for improvisation 
in terms that infer a high level of deliberate approach means the idea of preparation is very important for improvisation, where real-time cognitive processing often is pushed near its attention limits. ${ }^{48}$ For improvised performance that aims at artistic presentation, in which discrepancies between intention and result must be kept within strict bounds, practice must attempt to explore the full range of possible motor actions and musical effects to enable both finer control and the internal modeling of discrepancies and correction procedures, including feed-forward. In short, mastery of structure with DP facilitates eventual mastery of improvisation.

\section{Structure and Improvisation in Cardiac Surgery}

Surgery and the steps of an operation can range from highly predictable to markedly variable depending on the complexity of the defect (Figure 7). CVS operations that are simple or straightforward (eg, atrial septal defect closure, coronary bypass grafting) are typically set up and performed the same way every time. The operation is neatly orchestrated, structured, and reproducible. Deliberate and independent practice with memorization of steps and repetition of the technical aspects of the procedure can improve accuracy and efficiency of the procedure. The overall result and expected outcome are excellent and reproducible. This would be the equivalent of classical music. On the other hand, complex operations (eg, Ebstein anomaly and prosthetic valve endocarditis) or procedures using new technology often require more preparation, more practice, and advanced imaging. Although various aspects of the procedure are structured and reproducible, there are many other

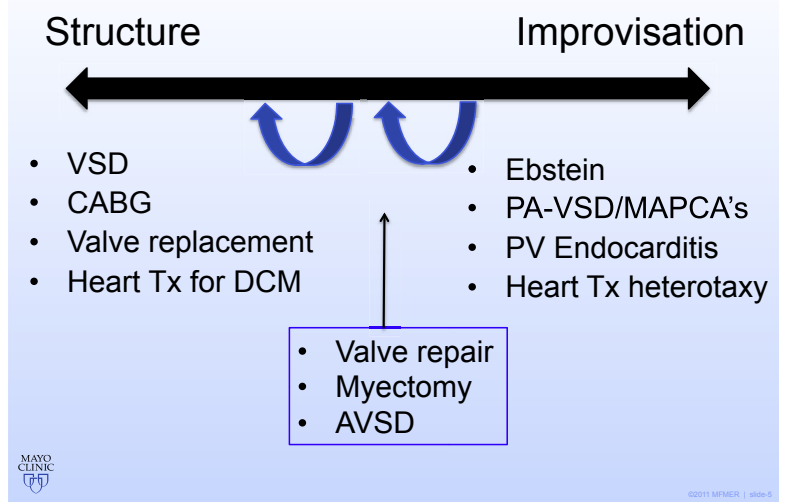

FIGURE 7. Structure/improvisation continuum with cardiac surgical procedures. Some are predictable and reproducible, and others are more variable. Advanced imaging and DP can facilitate moving the operation more leftward. $V S D$, Ventricular septal defect; $C A B G$, coronary artery bypass grafting; $T x$, transplant; $D C M$, dilated cardiomyopathy; $P A$, pulmonary atresia; $M A P C A$, major aortopulmonary collateral; $P V$, prosthetic valve; $A V S D$, atrioventricular septal defect. steps that are less certain and the surgeon must adapt and improvise through forthcoming steps. The expected result is less certain and more vulnerable to error. This would be equivalent to jazz. Although all types of surgery will always involve a combination of structured steps and improvised steps, advanced imaging, DP, and more experience facilitates a greater proportion of any procedure being more structured, which can facilitate an approach toward surgical perfection and optimize outcome.

With these questions in mind, it would seem that the concept of DP from the field of jazz improvisation would support the argument that DP for surgeons performing complex procedures or using robotics to successfully carry out highly specialized procedures in which the need for incremental levels (or higher) of improvisation can occur is both appropriate and essential.

\section{CONCLUSIONS}

Advances in anatomic imaging, specifically 3D printed models, can facilitate preoperative practice of the planned surgical procedure. Expert performance, particularly in surgery, requires both deliberate and independent practice. The orchestration of an operation involves structured steps (ie, predictable and reproducible) and improvised steps (ie, spontaneous adaptation because of complexity or unexpected findings). Although every operation involves a combination of both structured and improvised steps, the more structure that can be applied to a procedure, the greater the likelihood of a predictably good outcome. To achieve surgical perfection, surgeons should focus their efforts on continuous improvement by integrating advanced imaging with DP routines designed for highly specific events so operations can be choreographed in a manner that optimizes the structure/improvisation continuum.

\section{Conflict of Interest Statement}

Authors have nothing to disclose with regard to commercial support.

\section{References}

1. Ericsson KA, Krampe RT, Tesch-Romer C. The role of deliberate practice in the acquisition of expert performance. Psychol Rev. 1993;100:363-406.

2. Ericsson KA. Deliberate practice and the acquisition and maintenance of expert performance in medicine and related domains. Acad Med. 2004;79:S70-81.

3. Antiel RM, Van Arendonk KJ, Reed DA, Terhune KP, Tarpley JL, Porterfield JR, et al. Surgical training, duty-hour restrictions, and implications for meeting the Accreditation Council for Graduate Medical Education core competencies: views of surgical interns compared with program directors. Arch Surg. 2012; 147:536-41.

4. Matyal R, Mitchell JD, Hess PE, Chaudary B, Bose R, Jainandunsing JS, et al. Simulator-based transesophageal echocardiographic training with motion analysis: a curriculum-based approach. Anesthesiology. 2014;121:389-99.

5. Stefanidis D, Scerbo MW, Montero PN, Acker CE, Smith WD. Simulator training to automaticity leads to improved skill transfer compared with traditional proficiency-based training: a randomized controlled trial. Ann Surg. 2012;255:30-7.

6. Rosenthal ME, Ritter EM, Goova MT, Castellvi AO, Tesfay ST, Pimentel EA, et al. Proficiency-based fundamentals of laparoscopic surgery skills training 
results in durable performance improvement and a uniform certification pass rate. Surg Endosc. 2010;24:2453-7.

7. Scott DJ, Cendan JC, Pugh CM, Minter RM, Dunnington GL, Kozar RA. The changing face of surgical education: simulation as the new paradigm. J Surg Res. 2008;147:189-93.

8. Wintersperger BJ, Bamberg F, De Cecco CN. Cardiovascular imaging: the past and the future, perspectives in computed tomography and magnetic resonance imaging. Invest Radiol. 2015;50:557-70.

9. Stankovic Z, Allen BD, Garcia J, Jarvis KB, Markl M. 4D flow imaging with MRI. Cardiovasc Diagn Ther. 2014;4:173-92.

10. de Zelicourt DA, Haggerty CM, Sundarswaran KS, Whited BS, Rossignac JR, Kanter KR, et al. Individualized computer-based surgical planning to address pulmonary arteriovenous malformations in patients with a single ventricle with an interrupted inferior vena cava and azygous continuation. J Thorac Cardiovasc Surg. 2011;141:1170-7.

11. LaPar DJ, Ailawadi G, Isbell JM, Crosby IK, Kern JA, Rich JB, et al. Mitral valve repair rates correlate with surgeon and institutional experience. J Thorac Cardiovasc Surg. 2014;148:995-1004.

12. Joyce DP, Dhillon TS, Caffarelli AD, Joyce DD, Tsirigotis DN, Burdon TA, et al. Simulation and skills training in mitral valve surgery. J Thorac Cardiovasc Surg. 2011;141:107-12.

13. Hossien A. Intermediate-fidelity simulator for self-training in mitral valve surgery. Multimed Man Cardiothorac Surg. 2016;2016.

14. de Mel A. Three-dimensional printing and the surgeon. Br J Surg. 2016;103: 786-8.

15. Owais K, Pal A, Matyal R, Montealegre-Gallegos M, Khabbaz KR, Maslow A, et al. Three-dimensional printing of the mitral annulus using echocardiographic data: science fiction or in the operating room next door? J Cardiothorac Vasc Anesth. 2014;28:1393-6.

16. Hermsen JL, Burke TM, Seslar SP, Ownes DS, Ripley BA, Mokadam NA, et al. Scan, plan, practice, perform: development and use of a patient-specific 3-D printed model in adult cardiac surgery. J Thorac Cardiovasc Surg. 2017;153: 132-40.

17. Mahmood F, Owais K, Taylor C, Montealegre-Gallegos M, Manning W, Matyal R, et al. Three-dimensional printing of mitral valve using echocardiographic data. JACC Cardiovasc Imaging. 2015;8:227-9.

18. Mashari A, Knio Z, Jeganathan J, Montealegre-Gallegos M, Yeh L, Amador Y, et al. Hemodynamic testing of patient-specific mitral valves using a pulse duplicator: a clinical application of three-dimensional printing. J Cardiothorac Vasc Anesth. 2016;30:1278-85

19. Ericsson KA. Acquisition and maintenance of medical expertise: a perspective from the expert-performance approach with DP. Acad Med. 2015;90:1471-86.

20. Anwar S, Singh GK, Varughese J, Nguyen H, Billadello JJ, Sheybani EF, et al. 3D printing in complex congenital heart disease: across a spectrum of age, pathology, and imaging techniques. JACC Cardiovasc Imaging. July 14, 2016 [Epub ahead of print].

21. Yang DH, Kim DH, Handschumacher MD, Levine RA, Kikm JB, Sun BJ, et al. In vivo assessment of aortic root geometry in normal controls using 3D analysis of computed tomography. Eur Heart J Cardiovasc Imaging. July 26, 2016 [Epub ahead of print].

22. Gillaspie EA, Matsumoto JS, Morris NE, Downey RJ, Shen KR, Allen MS, et al. From 3-dimensional printing to 5-dimensional printing: enhancing thoracic surgical planning and resection of complex tumors. Ann Thorac Surg. 2016;101: 1958-62.

23. Ericsson KA, Prietula MJ, Cokely ET. The making of an expert. Harv Bus Rev. July-August 2007;85:114-21, 193. Available at: http://harvardbusiness.org/ product/makingof-an-expert/an/R0707J-PDF-ENG. Accessed May 22, 2017.

24. Carpenter AJ, Yang SC, Uhlig PN, Colson YL. Envisioning simulation in the future of thoracic surgical education. J Thorac Cardiovasc Surg. 2008;135: 477-84.

25. Marshall MB. Simulation for technical skills. J Thorac Cardiovasc Surg. 2012; 144:S43-7.
26. Tan SSY, Sarker SK. Simulation in surgery: a review. Scott Med J. 2011;56: 104-9.

27. Nesbitt JC, Julien JS, Absi TS, Ahmad RM, Grogan EL, Balaguer JM, et al. Tissue-based coronary surgery simulation: medical student DP can achieve equivalency to senior surgery residents. J Thorac Cardiovasc Surg. 2013; 145:1453-9.

28. Burkhart HM, Riley JB, Hendrickson MA, Glenn GF, Lynch JJ, Arnold JJ, et al. The successful application of simulation-based training in thoracic surgery residency. J Thorac Cardiovasc Surg. 2010;139:707-12.

29. Burkhart HM, Riley JB, Lynch JJ, Suri RM, Greason KL, Joyce LK, et al. Simulation -based postcardiotomy extracorporeal membrane oxygenation crisis training for thoracic surgery residents. Ann Thorac Surg. 2013;95:901-6.

30. Seymour NE, Gallagher AG, Romas SA, O’Brien MK, Bansal VK, Andersen DK, et al. Virtual reality training improves operating room performance: results of a randomized, double-blinded study. Ann Surg. 2002;236:458-63.

31. Fann JI, Caffarelli AD, Georgette G, Howard SK, Gaba DM, Youngblood P, et al. Improvement in coronary anastomosis with cardiac surgery simulation. J Thorac Cardiovasc Surg. 2008;136:1486-91.

32. Price J, Naik V, Boodhwani M, Brandys T, Hendry P, Lam BK. A randomized evaluation of simulation training on performance of vascular anastomosis on a high-fidelity in vivo model: the role of DP. J Thorac Cardiovasc Surg. 2011; 142:496-503.

33. Fann JI, Calhoon JH, Carpenter AJ, Merrill WH, Brown JW, Poston RS, et al. Simulation in coronary artery anastomosis early in cardiothoracic surgical residency training: The Boot Camp Experience. J Thorac Cardiovasc Surg. 2010; 139:1275-81.

34. Oremakinde AA, Bernstein MA. Reduction in errors is associated with prospectively recording them. J Neurosurg. 2014;121:297-304.

35. Vickers AJ, Bianco FJ, Serio AM, Eastham JA, Schrag D, Klein EA, et al. The surgical learning curve for prostate cancer control after radical prostatectomy. J Natl Cancer Inst. 2007;99:1171-7.

36. Vickers AJ, Bianco FJ, Gonen M, Cronin AM, Eastham JA, Schrag D, et al. Excellent rates of cancer control for patients with organ-confined disease treated by the most experienced surgeons suggest that the primary reason such patients recur is inadequate surgical technique. Eur Urol. 2008;53:960-6.

37. Ericsson KA, Pool R. Peak: Secrets From the New Science of Expertise. New York: Houghton Mifflin \& Harcourt; 2016.

38. Liu D, Grundgeiger T, Sanderson PM, Jenkins SA, Leane TA. Interruptions and blood transfusion checks: lessons from the simulated operating room. Anesth Analg. 2009;108:219-22.

39. Gladwell M. Outliers: The Story of Success. Boston, MA: Little, Brown and Company; 2008.

40. Ericsson KA, Lehmann AC. Expert and exceptional performance: evidence of maximal adaptation to task constraints. Annu Rev Psychol. 1996;47:273-305.

41. Macnamara BN, Hambrick DZ, Oswald FL. DP and performance in music, games, sports, education, and professions: a meta-analysis. Psychol Sci. 2014; 25:1608-18.

42. Macnamara BN, Moreau D, Hambrick DZ. The relationship between DP and performance in sports: a meta-analysis. Perspect Psychol Sci. 2016;11:333-50.

43. Ericsson KA. Summing up hours of any type of practice versus identifying optimal practice activities: commentary on Macnamara, Moreau, \& Hambrick. Perspect Psychol Sci. 2016;11:351-4.

44. Wing A, Daffertshofer A, Pressing J. Multiple time scales in serial production of force: a tutorial on power spectral analysis of motor variability. Hum Mov Sci. 2004;23:569-90.

45. Welford AT. Skilled Performance. Glenview, IL: Scott, Foresman and Co; 1976.

46. Welford AT. Motivation, capacity, learning and age. Int J Aging Hum Dev. 1976; 7:189-99.

47. Sparrow WA. The efficiency of skilled performance. J Mot Behav. 1983;15: 237-61.

48. Kickert WJM, Bertrand JWM, Praagman J. Some comments on cybernetics and control. Trans Syst Mand Cybern. 1978;8:805-9. 